\title{
Characterization of Prokaryotic and Eukaryotic Microbial Community in Pacific White Shrimp Ponds
}

\author{
Dongwei Hou ${ }^{1 \#}$, Shenzheng Zeng ${ }^{1 \#}$, Jian Liu1, Muting Yan², Shaoping Weng ${ }^{2}$, Jianguo He ${ }^{1,2 *}$ and Zhijian Huang ${ }^{1 *}$
}

${ }^{1}$ State Key Laboratory of Biocontrol, Institute of Aquatic Economic Animals and Guangdong Province Key Laboratory for Aquatic Economic Animals, Guangdong Provincial Key Laboratory of Marine Resources and Coastal Engineering, School of Marine Sciences, Sun Yat-sen University, Guangzhou 510275, PR China

${ }^{2}$ School of Life Sciences, Sun Yat-sen University, Guangzhou 510275, PR China

\#Equally contributed

\begin{abstract}
This research profiles the community compositions and dominant taxonomies of prokaryotic and eukaryotic microbes in 30 samples of the water from 5 different Pacific white shrimp ponds. The V4 region of the 16S rRNA gene and $18 \mathrm{~S}$ rRNA gene were sequenced by high-throughput sequencing technology. Total of $1,387,317$ 16S rRNA and 1,612,056 18S rRNA gene fragments were selected for classification, including 3,841 prokaryotic Operational Taxonomic Units (OTUs) and 990 eukaryotic OTUs. It's observed that all of the 16S rRNA sequences were affiliated with at least 47 bacteria divisions and 18S rRNA sequences were affiliated with 50 eukaryotic divisions, respectively. Among all 30 samples, the dominant prokaryotic and eukaryotic community at phylum level shared considerable similarity in composition but not in abundance. The dominant prokaryotic community included Actinobacteria, Proteobacteria, Cyanobacteria, Planctomycetes, Verrucomicrobia, Bacteroidetes, Chlorobi, Chloroflexi, Firmicutes and Spirochaetes. Cercozoa, Chlororhyta, Arthropoda, Stramenopiles-unidentified, Fungi-unidentified, Prymnesiophyceae, Ciliophora, Mollusca, Choanomonada and Jakobida were the dominant compositions of the eukaryotic. Similarly, significant difference existed at the genus level among the 30 samples. Results of richness and diversity showed that prokaryotic and eukaryotic microbes possessed complex community compositions in 5 ponds. While in different periods and different ponds, the value of Chao, Ace, Shannon and Simpson index were not significantly different $(P>0.05)$.
\end{abstract}

Keywords: Eukaryotic community; Prokaryotic community; Highthroughput sequencing technology; Shrimp

\section{Introduction}

Shrimp is one of the most important products of fishery trading commodities [1]. During 2008 to 2013, the total world shrimp production was in the range of 3,400 4,450 kt [2]. China is the largest producer of shrimp, whose contribution to the total world shrimp production was approximately $40 \%$ [2]. The Pacific white shrimp, Litopenaeus vannamei, has become one of the most profitable aquaculture species and accounts for about $85 \%$ of total shrimp production in mainland of China [3].

In China, the fast growth rate and high density cultivation of aquaculture was based on the larger amount of energy and nutrition inputs, which caused the water eutrophication and made the microbial communities change easily. Water eutrophication may lead to algae blooms, such as Cyanobacteria bloom. In aquatic ecosystem, Cyanobacteria bloom can restrict light penetration, deplete oxygen levels, and decrease the numbers of submerged plants, killing of aquatic animals and modifying the food web dynamics [4,5]. Thus, it is of great significance to investigate the community compositions of prokaryotic and eukaryotic microbes in aquaculture ponds. A recent study [6] shows that season changes have more effects on the bacterial community than what the stocking density does in the pond water of tilapia. And the most communities were affected by the nutrient, except phylum Cyanobacteria was also affected by the feed control. Another study [7] on phytoplankton community in shrimp ponds indicates that the changes in physical factors and nutrient levels contribute to the dominant species changes from week to week, and Diatom shows dominancy in almost every week during the cultivation period. Besides, the study [8] in shrimp ponds water shows that the bacterial community structure in the intensive ponds differs from those in the extensive ponds and the bacterial community structure in the intensive ponds are variable depending on the water treatment system. These results suggest that profiles of bacterial community structure may become a biological indicator to evaluate the water constituents in the aquaculture ponds.

In a typical aquatic ecosystem, microbial communities play important roles in food net, being the producer, consumer and decomposer at the same time. Previous studies used to focus on the bacterial community in the shrimp ponds, sediment and intestinal extractive [7-10]. Traditional methods studying microbial community like microscopic identification and plate cultivation hold apparent short comings, including the disability in detecting a mass of uncultured species. Some biochemical methods, such as phospholipid fatty acids (PLFA) [11,12], denaturing gradient gel electrophoresis (DGGE) [9] and clone library analysis [13], have also been used to characterize the microbial community compositions, which have certain limitations because they tend to underestimate the overall diversity and it is difficult to profile a comprehensive community in complex environments. Fortunately, the high-throughput sequencing

*Corresponding authors: Zhijian Huang, State Key Laboratory of Biocontrol, Institute of Aquatic Economic Animals and Guangdong Province Key Laboratory for Aquatic Economic Animals, Guangdong Provincial Key Laboratory of Marine Resources and Coastal Engineering, School of Marine Sciences, Sun Yat-sen University, Guangzhou 510275, PR China, Tel: +86 208411 2828; E-mail: Isshzhj@mail.sysu.edu.cn

Jianguo He, School of Life Sciences, Sun Yat-sen University, Guangzhou 510275, PR China, Tel: +86 208411 2828; E-mail: Isshjg@mail.sysu.edu.cn

Received November 25, 2016; Accepted December 21, 2016; Published December 23, 2016

Citation: Hou D, Zeng S, Liu J, Yan M, Weng S, et al. (2016) Characterization of Prokaryotic and Eukaryotic Microbial Community in Pacific White Shrimp Ponds. J Aquac Res Development 7: 463. doi: 10.4172/2155-9546.1000463

Copyright: (C) 2016 Hou D, et al. This is an open-access article distributed unde the terms of the Creative Commons Attribution License, which permits unrestricted use, distribution, and reproduction in any medium, provided the original author and source are credited. 
technology has become a powerfully tool to analyze microbial community of environmental samples $[14,15]$, which could generate reliable and sufficient information on community compositions through the amplification and identification of $16 \mathrm{~S}$ rRNA and $18 \mathrm{~S}$ rRNA genes. Generally, the high-throughput sequencing technology is an ideal method for microbial community analyses.

Although various studies reported the bacterial community in aquaculture ponds, the relatively complete community compositions of prokaryotic and eukaryotic microbes in shrimp ponds have not been reported. Thus, the aim of our study was to investigate prokaryotic and eukaryotic community by the high-throughput sequencing technology in order to enlarge our understanding of microbial communities in shrimp ponds.

\section{Materials and Methods}

\section{Sample collection}

Water samples were collected from five shrimp ponds, which located in Maoming, Guangdong Province, China $\left(21.68^{\circ} \mathrm{N}, 110.88^{\circ} \mathrm{E}\right)$. The surface area of the ponds was approximate $2,600 \mathrm{~m}^{2}$ and the average depth was $1.5 \mathrm{~m}$. Water was pumped from the nearby seawater whose salinity was approximate $10 \%$. Shrimp larvae were from Guangdong Huanqiu Aquaculture Company and 200,000 shrimp larvae were cultured in each pond. The feed was from Guangdong Haida Group Co. Water samples were collected every 15 days and finally 30 samples were gained. For simplification, the 5 ponds from which the samples were collected were named as A, B, C, D and E. Samples from the same pond were named $1,2,3,4,5$ and 6 , based on the collected date. Thus, 30 samples were named as A1 A6, B1 B6, C1 C6, D1 D6 and E1 E6.

$1.5 \mathrm{~L}$ of water was taken for the following experiments [6]. The water temperature, $\mathrm{pH}$ value and salinity were monitored in situ with an YSI handheld multiparameter instrument (Model YSI 556, YSI, USA). $0.5 \mathrm{~L}$ water was taken to determine the concentration of sulfate, orthophosphate and dissolved inorganic nutrients $\left(\mathrm{NO}_{2}-\mathrm{N}, \mathrm{NO}_{3}-\mathrm{N}\right.$ and $\mathrm{NH}_{4}-\mathrm{N}$ ) by automatic discrete analyzer (Model CleverChem 200, DeChem-Tech, Germany). 1.0 L mixture water was filtered the biomass with $0.22 \mu \mathrm{m}$ and $0.45 \mu \mathrm{m}$ filter for the prokaryote and eukaryotes, respectively. The filter membranes were stored at $-80^{\circ} \mathrm{C}$ before DNA extraction.

\section{DNA extraction and sequencing}

The filter membranes were put into a $50 \mathrm{~mL}$ centrifuge tube containing sterile glass beads and $10 \mathrm{~mL}$ PBS buffer was added. The tube was vortex thoroughly for $3 \mathrm{~min}$ and centrifuged at $10,000 \mathrm{~g}$ for $1 \mathrm{~min}$, reducing the influence of unknown material. Genome DNA was extracted using the Water DNA Kit (Omega Bio-tek, USA) according to the manufacturer's directions. The concentration and purity of genome DNA were determined by the NanoVuePlus Spectrophotometer (GE Healthcare, USA). DNA was diluted to 1ng/ $\mu \mathrm{L}$ using sterile water. The V4 hypervariable region of 16S rRNA gene was amplified with the primers 515F (5'-GTGCCGCGGTAA-3') and 806R (5'-GGACTACHVGGGTWTCTA AT-3') [16]. The V4 hypervariable region of $18 \mathrm{~S}$ rRNA gene was amplified with the primer pair 528F (5'-GCGGTAATTCCAGCTCCAA-3') and 706R (5'-AATCCRAGAATTTCACCTCT-3') [17]. The PCR program was as follows: $95^{\circ} \mathrm{C}$ for $5 \mathrm{~min} ; 94^{\circ} \mathrm{C}$ for $30 \mathrm{~s} ; 50^{\circ} \mathrm{C}$ for $10 \mathrm{~s}$; $72^{\circ} \mathrm{C}$ for 20s. Run for 35 cycles. All PCR reactions were carried out with Phusion High-Fidelity PCR Master Mix (New England Biolabs, UK) PCR products were mixed in equidensity ratios. Sequencing libraries were generated using TruSeq DNA PCR-Free Sample Preparation
Kit (Illumina, USA) following manufacturer's recommendations and index codes were added. The library quality was assessed on Qubit 2.0 Fluorometer (Thermo Scientific, USA). The library was sequenced by Illumina Hiseq2500 system (Illumina, USA), conducted by Novogene Bioinformatics Technology Co. Ltd (Beijing, China).

\section{Data analysis}

Raw data generated from the Hiseq2500 system were merged with FLASH (Version 1.2.7, http://ccb.jhu.edu/software/FLASH/) [18]. In order to control the quality process, raw tags were then filtered to obtain the high-quality clean tags by the QIIME (Version 1.7.0, http://qiime. org/index.html) $[19,20]$. To detect and remove the chimera sequences, the tags were compared with the Gold database (http://drive5.com/ uchime/uchime_download.html) using UCHIME algorithm (http:// www.drive5.com/usearch/manual/uchime_algo.html) [21] and finally the effective tags were obtained. The effective tags analysis was completed by Uparse (Version 7.0.1001) to produce OTUs. Sequences with more than $97 \%$ similarity were assigned as the same OTU. The Green Gene Database (http://greengenes.lbl.gov/cgi-bin/nph-index. cgi) [22] was used to annotate taxonomic information for each representative sequence with the usage of RDP classifier (Version 2.2, http://sourceforge.net/projects/rdp-classifier) [23]. To figure out the phylogenetic relationship of different OTUs and the dominant species in different samples, multiple sequence alignment were conducted and UPGMA tree was made by Muscle (Version 3.8.31, http://www.drive5. $\mathrm{com} / \mathrm{muscle)}$ [24]. OTUs abundance information was normalized with a standard of sequence number which was correspond to the sample that contained the least sequences [25]. The following analysis was based on the output normalized data. The relative abundance of individual taxa within each sample can be obtained by comparing the number of total sequences and sequences can be assigned to a specific taxon [26]. Alpha diversity was calculated of Chao index, Ace index, Shannon index and Simpson index value by QIIME (Version 1.7.0).

\section{Results}

\section{Environmental parameters}

The water temperature was relatively stable at approximately $30^{\circ} \mathrm{C}$. $p H$ value ranged from 7.5 to 8.61 . Irregular changes in $\mathrm{NH}_{3}-\mathrm{N}$, $\mathrm{NO}_{2}-\mathrm{N}, \mathrm{NO}_{3}-\mathrm{N}, \mathrm{PO}_{4}^{3-}$ and $\mathrm{SO}_{4}^{2-}$, were in range of $0.0089 \sim 1.1095 \mathrm{mgL}^{-1}$, $0.0022 \sim 0.9869 \mathrm{mgL}^{-1}, 0.0323 \sim 3.3007 \mathrm{mgL}^{-1}, 0.0171 \sim 0.3131 \mathrm{mgL}^{-1}$ and $0.0012 \sim 0.3777 \mathrm{mgL}^{-1}$, respectively.

\section{Community of prokaryotic and eukaryotic at phylum level}

Total of 1,387,317 $16 \mathrm{~S}$ rRNA and 1,612,056 18S rRNA gene fragments were selected for classification. 3,841 prokaryotic OTUs and 990 eukaryotic OTUs were gained. The dominant length distributions were approximately $253 \mathrm{bp}$ and $310 \mathrm{bp}$, respectively.

All of the 16S rRNA sequences were affiliated with at least 47 bacteria divisions (Figure 1a). Most of all sequences belonged to the following ten phyla, included Actinobacteria, Proteobacteria, Cyanobacteria, Planctomycetes, Verrucomicrobia, Bacteroidetes, Chlorobi, Chloroflexi, Firmicutes and Spirochaetes. The major phyla were always more than $90 \%$ proportion among all samples. The highest Actinobacteria proportions were exhibited in sample D1 and D6. The proportions of Cyanobacteria were more than $10 \%$ except in 6 samples (A5, C5, D1, D4, D5 and D6). The highest proportions were in sample A3 (36.38\%) and B6 (36.94\%). The highest and lowest Proteobacteria proportions were in sample C5 and E2, $45.72 \%$ and $17.81 \%$ respectively. Chlorobi always existed in all samples. 
Citation: Hou D, Zeng S, Liu J, Yan M, Weng S, et al. (2016) Characterization of Prokaryotic and Eukaryotic Microbial Community in Pacific White Shrimp Ponds. J Aquac Res Development 7: 463. doi: 10.4172/2155-9546.1000463
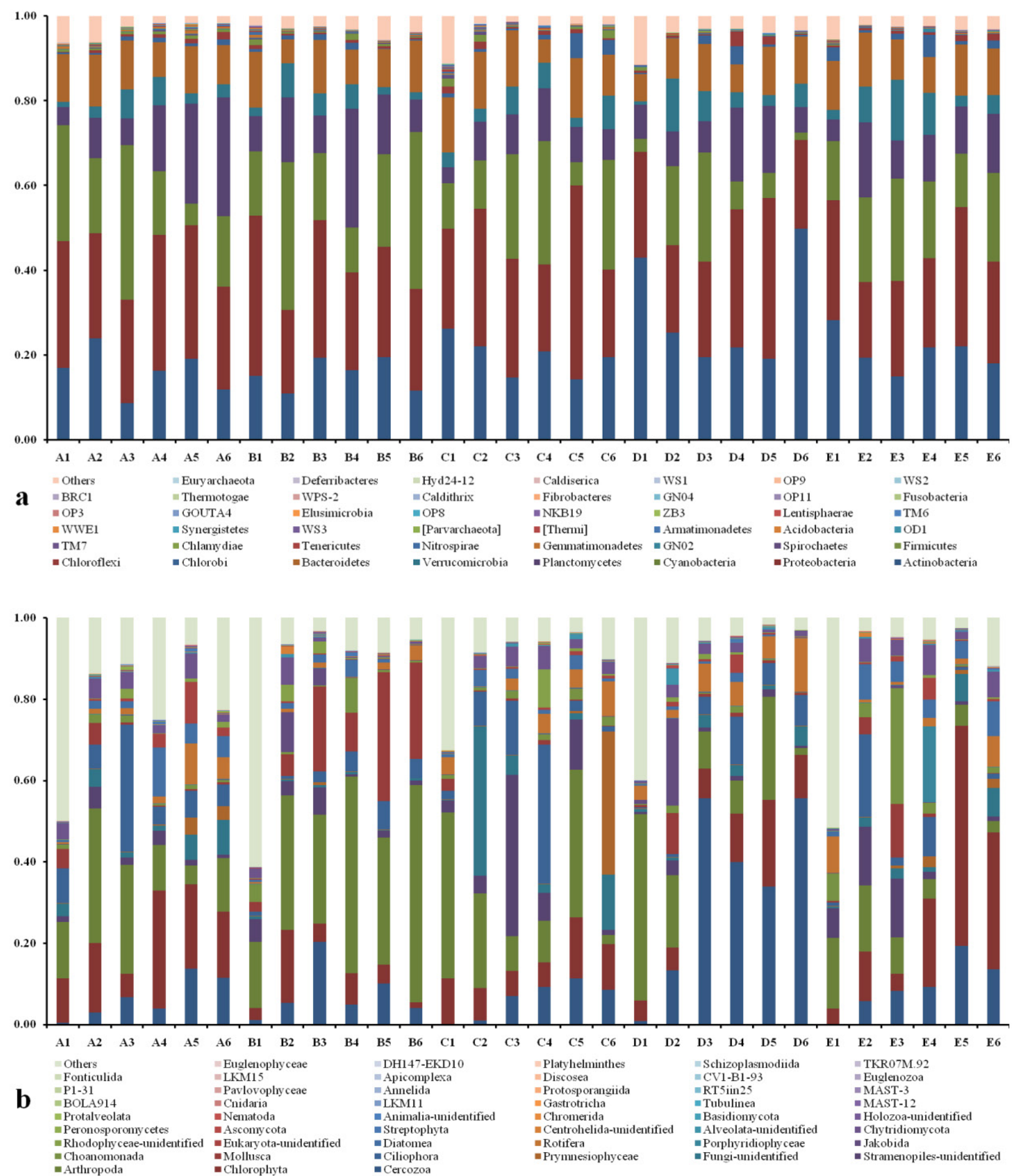

Figure 1: Phylum level relative abundance and community compositions of prokaryotic (a) and eukaryotic (b) obtained by $16 \mathrm{~S}$ rRNA and $18 \mathrm{~S}$ rRNA sequencing in 30 samples. The phylum level distribution presented is based on the $80 \%$ similarity clusters OTUs. Sequences whose relative abundance was lower than $1 \%$ and unclassified were assigned as "others".

All of the $18 \mathrm{~S}$ rRNA sequences were affiliated with at least 50 divisions at phylum level (Figure 1b), and minority divisions were identified as phytoplankton. The majority of all eukaryotic community belonged to the following ten divisions: Cercozoa, Chlororhyta, Arthropoda, Stramenopiles-unidentified, Fungi-unidentified,
Prymnesiophyceae, Ciliophora, Mollusca, Choanomonada and Jakobida. Cercozoa proportions were over $55 \%$ in sample D3 and D6. More than half of all samples, Chlororhyta and Arthropoda proportions were higher than $10 \%$. Ciliophora and Mollusca always existed in all samples, which were highest in sample C4 (34.17\%) and 
Citation: Hou D, Zeng S, Liu J, Yan M, Weng S, et al. (2016) Characterization of Prokaryotic and Eukaryotic Microbial Community in Pacific White Shrimp Ponds. J Aquac Res Development 7: 463. doi: 10.4172/2155-9546.1000463

B5 (31.69\%), respectively. In sample E3, Choanomonada proportion was well far above those of other samples. Diatomea, Cladocera and Copepods are usually considered conducive to shrimp growth as the important source of food. Diatomea existed in all samples, which were the highest in sample A4 (12.14\%), E2 (8.71\%) and E6 (8.54\%), respectively. Diatomea proportions were higher than $1 \%$ of 17 samples. Cladocera and Copepods were not detected.

\section{Genus level on prokaryotic and eukaryotic community}

The clustering heatmap was based on the top 35 abundant prokaryotic and eukaryotic community at the genus level (Figure 2). The most abundant prokaryotic at genus level were Microcystis, Candidatus Aquiluna, Oceanibaculum, Gemmatimonas, Bdellovibrio, Bacteriovorax, KSA1, Rhodobacter, Candidatus Xiphinematobacter,

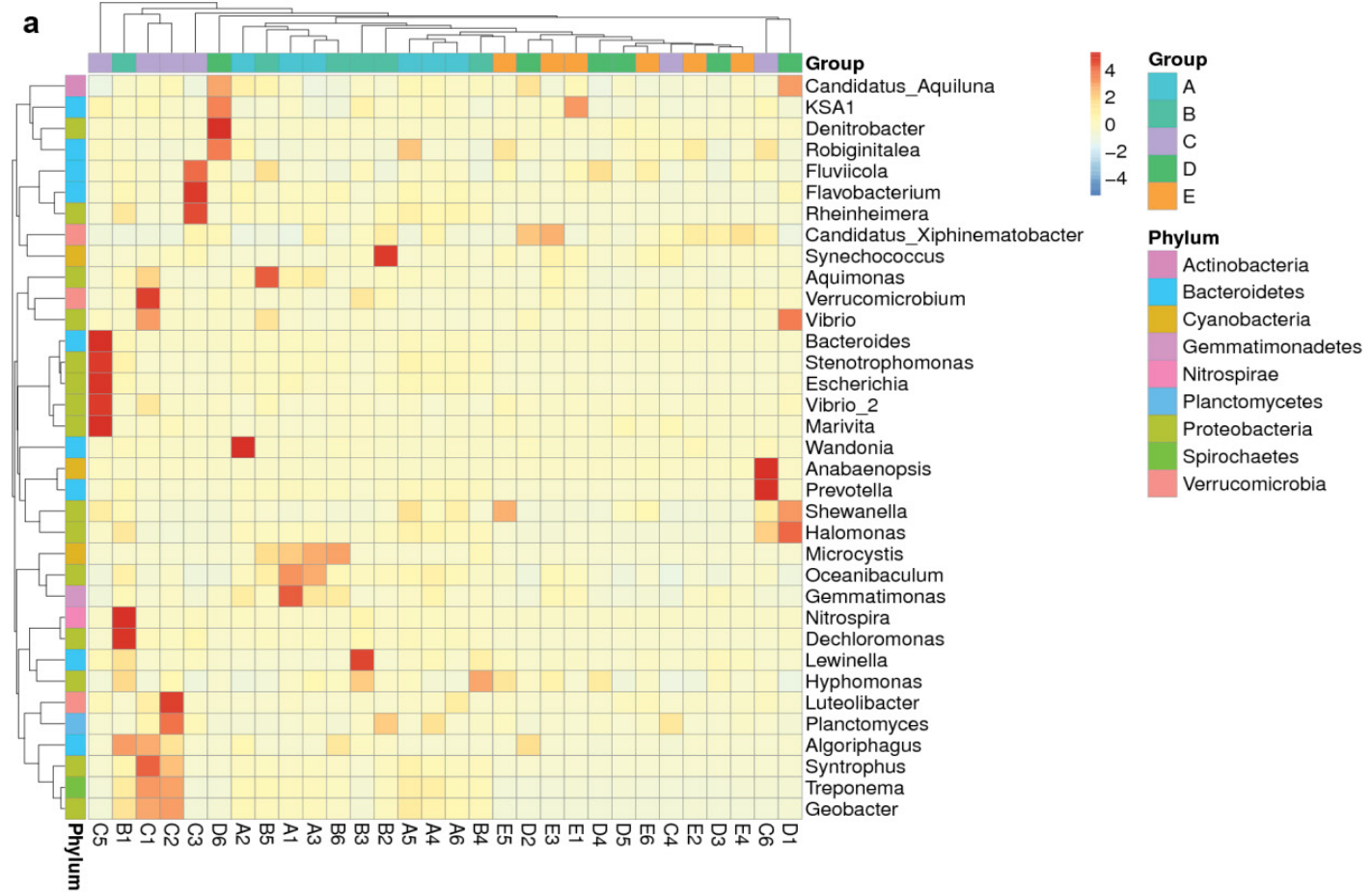

b

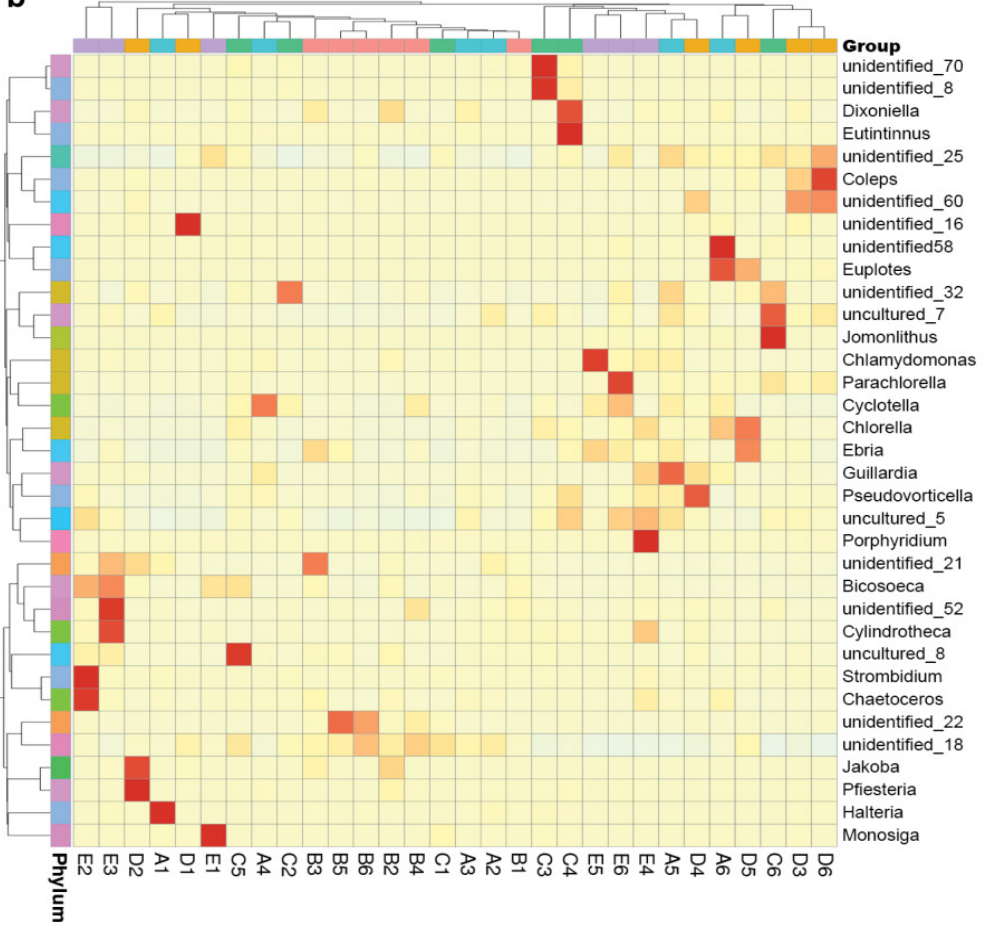

\begin{tabular}{|cc}
\hline 4 & Group \\
2 & A \\
0 & B \\
-2 & C \\
-4 & D \\
\hline & E
\end{tabular}

Phylum

Arthropoda

Cercozoa

Chlorophyta

Choanomonada

Chytridiomycota

Ciliophora

Diatomea

Jakobida

Mollusca

Porphyridiophyceae

Prymnesiophyceae

Rotifera

unidentified

Figure 2: Heatmap analysis of prokaryotic (a) and eukaryotic (b) community at the genus level based on the 16S rRNA and 18S rRNA sequencing profiles. In the figure, the longitudinal is the phylogentic analysis based on Unweighted Pair Group Method with Arithmetic (UPGMA), the transverse is the Q-type Cluster Analysis based on the abundance of different genus of each sample. 
Aquimonas, Hyphomonas and Synechococcus. Microcystis were most abundant in 4 samples, including sample A1, A2, B5 and B6, whose proportions were $24.90 \%, 30.36 \%, 20.98 \%$ and $32.21 \%$, respectively. Besides, Microcystis is several or dozens times higher than other samples. Oceanibaculum proportions were relatively stable at approximately $0.16 \%$. Synechococcus were always found in all samples and particularly abundant in sample B2 (14.12\%). The Vibrio and Pseudomonadaceae, are major dangerous pathogens, their proportions were less than $0.01 \%$. Bacillus, Lactobacillus and Yeast were used as probiotics in aquaculture. The proportion of Bacillus was less than $0.01 \%$ in 19 samples and not detected in 11 samples. In all samples, Lactobacillus and Yeast were not detected. The most abundant eukaryotic were Cercozoa-unidentified, Maxillopoda-unidentified, Chlamydomonas, Stramenopiles-unidentified, Jomonlithus, Gastropoda-unidentified, Ebria and Salpingoecidae-unidentified. Cercozoa-unidentified proportions were quite high in sample D3, D4, D5 and D6, even achieved $54.73 \%$ in sample D6. Two thirds of all samples, the proportions of Maxillopoda-unidentified were over 10\%, and the highest abundance was in sample B6 (53.32\%). Chlamydomonas, Stramenopiles - unidentified, Jomonlithus, Gastropoda-unidentified, Ebria, Salpingoecidae-unidentified, Bicosoeca, Parachlorella, Cyclotella and Chlorella were found in all samples with low proportions, and several of them were more than $10 \%$.

\section{Richness, diversity and similarity analysis}

The prokaryotic and eukaryotic richness of all samples from five ponds was indicated by Chao index and Ace index (Figure 3). There was no significant difference in Chao index and Ace index value of different ponds $(\mathrm{P}>0.05)$. The highest Chao index and Ace index value of prokaryotic community richness were in sample A5, B1, C6, D5 and E5, while the highest value of eukaryotic community richness were in sample A2, B2, C4, D2 and E2. Moreover, the prokaryotic and eukaryotic diversity of the water samples from five ponds was indicated by Shannon index and Simpson index (Table 1). These results suggested that the value of Shannon index and Simpson index showed no significant difference between different periods and different ponds $(\mathrm{P}>0.05)$. The highest Shannon index and Simpson index value of prokaryotic community diversity were in sample A4, B1, C1, D5 and E5. While the highest value of eukaryotic community diversity were in sample A6, B2, C4, D4 and E4.

To show their similarity, all samples were compared using Non-
Metric Multi-Dimensional Scaling (NMDS) (Figure 3). For prokaryotic community, 6 samples from the same pond were dispersed to different quadrant, but 5 ponds were not separated from each other. Likewise, eukaryotic community of different samples from the same pond was separated from each other, except 5 samples (including B2, B3, B4, B5 and B6) clustered together within pond B.

The prokaryote results showed that the class of Deltaprotebacteria and Betaprotebacteriathe were the specific bacterial taxa in pond A; the class of Cytophagia and Oscillatoriophycideae, the order of Chroococcales and Cytophagales, the family of Microcystaceae, the genus of Microcystis and Synechococcus were the specific bacterial taxa in pond B; the genus of Marivita was the specific bacterial taxa in pond $\mathrm{C}$; the phylum of Actinobacteria, the class of Acidimicrobiia and the order of Acidimicrobiales were the specific bacterial taxa in pond D. And the eukaryote results showed that the class of Mediophyceae was the specific bacterial taxa in pond A; the phylum of Mollusca, the class of Gastropoda and Maxillopoda were the specific bacterial taxa in pond B; the phylum of uncultured-phytoplankton and Stramenopiles, the family of Euplotia and the genus of Euplotes-rariseta were the specific bacterial taxa in pond $\mathrm{C}$; the phylum of uncultured- eukaryote and the order of NOR26 were the specific bacterial taxa in pond D; the phylum of Diatomea and the class of Craspedida were the specific bacterial taxa in pond E. In conclusion, the NMDS plots suggested that prokaryotic and eukaryotic community of different samples from the same pond were relatively dispersed.

\section{Discussion}

High-throughput sequencing was one of the most effective techniques to determine the identification and quantification of microbial community, which can generate a profile of the whole community in aquatic ecosystem [27,28]. Studies on prokaryotic and eukaryotic community compositions by $16 \mathrm{~S}$ rRNA and $18 S$ rRNA sequencing were seldom reported in the water of Pacific white shrimp ponds. The study on prokaryotic and eukaryotic community is very important for understanding the structure and function of the ecosystem for shrimp ponds.

Previous research has shown that large amount of nutrient input and high temperature may lead to the Cyanobacteria bloom [29], and high phosphate concentration usually encourages the growth of Cyanobacteria [30]. In shrimp culture period, the phosphate level was
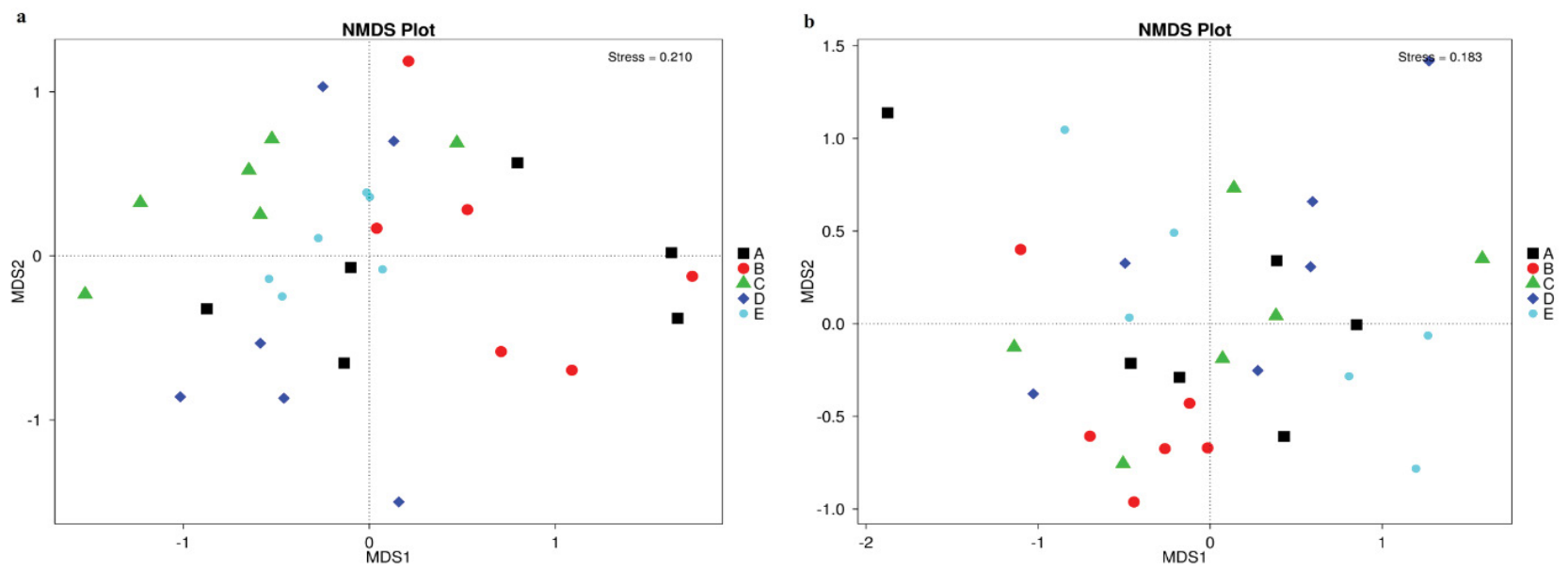

Figure 3: Grouping of prokaryotic (a) and eukaryotic (b) community according to taxonomic compositional similarity using by Non-Metric Multi-Dimensional Scaling analysis. Each symbol represents one sample, corresponding to a particular pond (color). 


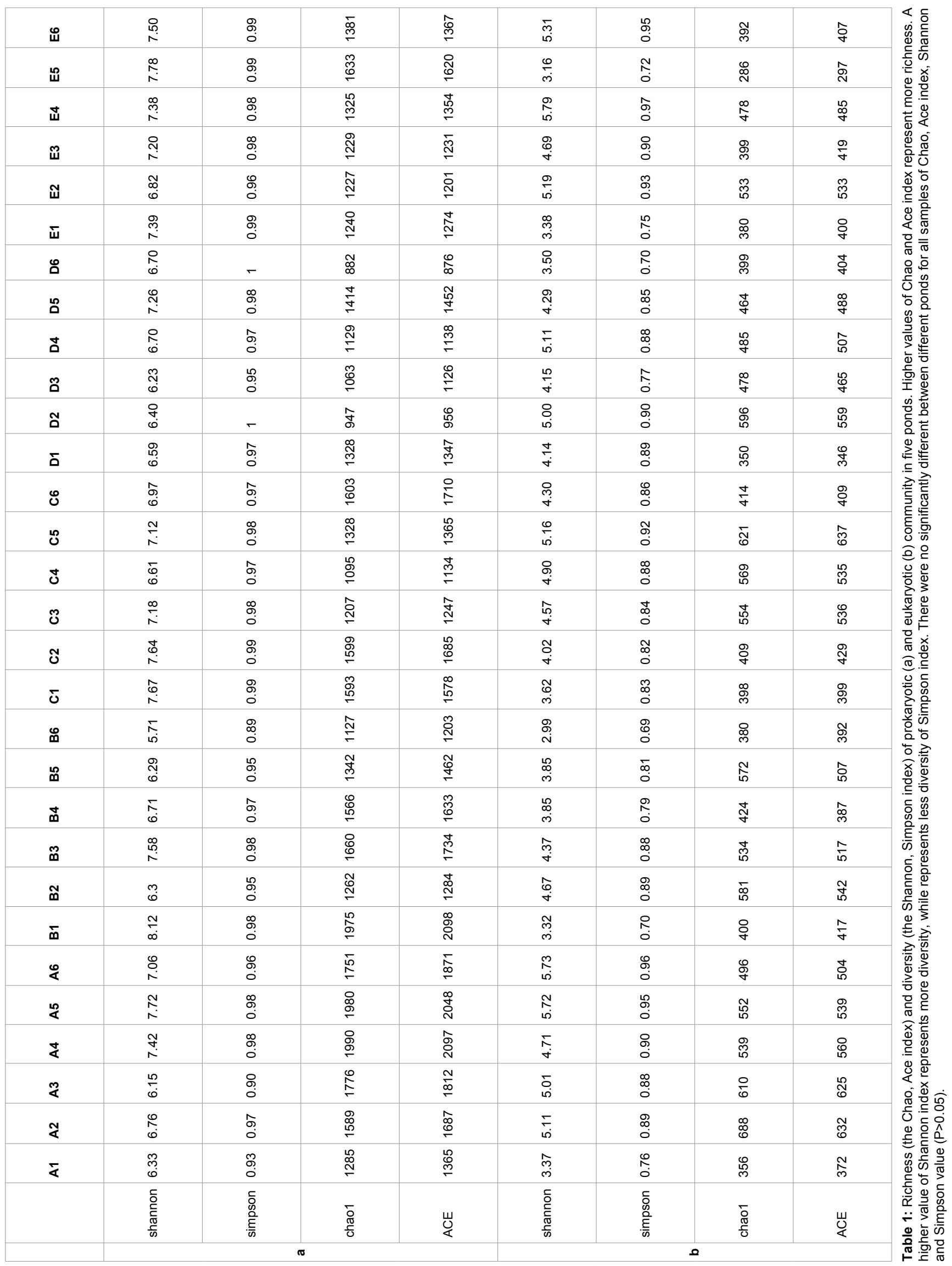


high due to the large amount of nutrition inputs including feeding and fertilization. Thus, we need to control phosphate input, thereby reduce the occurrence of Cyanobacteria bloom. In this study, the dominant prokaryotic bacteria, Actinobacteria, Proteobacteria and Cyanobacteria were found in the water of shrimp ponds. The results are not consistent with those of other methods. The sequencing results by 454 pyrosequencing technique [31] suggested that the major phylum in the shrimp ponds were Proteobacteria, Flavobacteria and Actinobacteria. DGGE [9] sequencing results showed that most species from fresh tropical shrimps (Penaeus notialis) ponds and the surrounding brackish water belonged to Firmicutes, followed by Proteobacteria and Actinobacteria. Except for regional difference, the discrepancy among the shrimp aquaculture water was mainly caused by the high percentage of uncultured clones and different methods used in the study. In addition, above results conflicted with the previous reports that Cyanobacteria was never the dominant phylum in shrimp ponds, whose proportions were normally less than $5 \%[9,11,32,33]$. However, at present study, Cyanobacteria proportions were higher than $10 \%$ among 24 samples.

Results in our study also showed that Microcystis and Synechococcus were the dominant genera among Cyanobacteria. It has been reported that high temperature is the main driving factor on the growth of Microcystis [34-36], and Microcystis survives better in high $\mathrm{pH}[37,38]$ and high phosphate level environments [39-41]. Consistent with the previous reports, the abundance of Microcystis was greatly increased in high temperature, $\mathrm{pH}$ and phosphate level circumstance in this research. Moreover, the temperature performed relatively as a stable environmental factor, while the high $\mathrm{pH}$ and high phosphate level were main effective factors on the growth of Microcystis. Synechococcus survived and propagated easily, acting as the main participants in the global carbon cycle and the major contributors to primary productivity [42], which is particularly abundant in offshore waters [43]. Bdellovibri was exhibited in all samples. As the obligate gram-negative predatory bacteria, Bdellovibri was always found in Cyanobacteria bloom. It was previously reported that Bdellovibrio can split Microcystis through breakdown of cell structures [44]. As the type of strictly anaerobic and photoautotrophic bacteria, Chlorobi may utilize sulfide or thiosulfate as an electron donor for $\mathrm{CO}_{2}$ accumulation [45]. Chlorobi were found in various types of aquaculture water $[6,46]$, in accordance with our results that Chlorobi was detected in all samples, which might result from significant hypoxia phenomena in 5 shrimp ponds. In order to ameliorate aquatic, effective microorganism (EM, include Yeast, Bacillus, Lactobacillus) was added to aquaculture ponds, frequently [39]. Yeast and Lactobacillus were not found in all samples, and Bacillus was also scarce only detected in 11 samples. These results indicated that the effective microorganism might have enormous pressure for survival in the water of shrimp ponds.

Compared with estuary and marine ecosystem [27,28], eukaryotic community compositions remains less understood in aquaculture water ecosystem. Unlike other aquatic ecosystem [47,48], the eukaryotic community in our study was dominated by Cercozoa, Chlorophyta and Arthropoda. Generally, zooplankton community was dominated by Arthropoda and Rotifera in a prawn (Macrobrachium rosenbergii) farm based on traditionally morphology [49]. While in this study, Cercozoa and Arthropoda were the highest abundance zooplankton community. Cercozoa is abundant in any protest phyla of every marine habitat, and act as a quantitatively significant player in carbon cycles and food webs by preying on bacteria and Diatom [50,51]. Our results showed that the Cercozoa proportion was limited during the early shrimp culture period, which might be caused by the changes of living environment, from offshore to the ponds with defined artificial treatments. Pseudodiaptomus annandalei and Apocyclopsroyi were the dominant species among Arthropoda. For Arthropoda, only Pseudodiaptomus annandalei existed in all samples except sample A1, whose predominant species was Apocyclopsroyi. Ammonium is the major nitrogenous waste excreted by Crustacea, including shrimps and zooplankton [52]. Chlorophyta, Stramenopiles, Haptophyta and Rhodophyceae were the most abundant phytoplankton community. Compared with other studies [53-55], Diatomea was not the dominant species in 5 ponds. Diatomea is considered conducive to shrimp growth as the important source of food. As a result most shrimp farm managers prefer a high proportion of Diatomea in phytoplankton community [56]. High nitrate concentration level and high N/P ratio will encourage the growth of diatom [57,58]. Thus, the low N/P ratio accounts partly for the low Diatomea proportion in this study. Besides, the number of zooplankton species was larger than phytoplankton, which was consistent with the previous research $[27,59]$. In general, previous studies focusing on phytoplankton community composition and function in aquaculture ecosystems, paid not enough attention on zooplankton $[5,37,53,54]$.

\section{Conclusion}

In summary, we generate a profile of the relatively complete prokaryotic and eukaryotic community in shrimp ponds. Our results showed that the abundance of microbial community is more linked to environmental factors (unpublished data). Hence, more intention should be paid to the effects of environmental factors on the diversity and distribution of microbial community, and the relationship between species and environmental factors in the ecosystem of shrimp ponds.

\section{Acknowledgement}

This work was financially supported by National Natural Science Foundation of China under Grant (No. U1131002), National Key Technology R\&D program (No. 2012BAD17B03), China Agriculture Research System (CARS-47) and Special Fund for Agro-scientific Research in the Public Interest (No. 201103034) Science and Technology Planning Project of Guangdong Province (No. 2012A020602084), Guangzhou Science Technology and Innovation Commission Project (No. 201510010071). Guangdong Ocean and Fishery Bureau Project (20164200042090023).

\section{Author's Contributions}

Dongwei Hou, Shaoping Weng, Zhijian Huang and Jianguo He conceived of the study, and participated in its design and coordination. Dongwei Hou drafted the manuscript, and extracted DNA. Shenzheng Zeng participated in the design of the study and extracted DNA. Jian Liu collected the samples. Muting Yan helped to draft the manuscript. All authors read and approved the final manuscript.

\section{References}

1. Moretti VM, Turchini GM, Bellagamba F, Caprino F (2003) Traceability issues in fishery and aquaculture products. Veterinary Research Communications 27 Suppl 1: 497-505.

2. FAO (2015) Fishery and aquaculture statistics. Food and Agriculture Organization of the United Nations, Rome.

3. Li F, Xiang J (2013) Recent advances in researches on the innate immunity of shrimp in China. Developmental and comparative immunology 39: 11-26.

4. Turner AM, Chislock MF (2010) Blinded by the stink: Nutrient enrichment impairs the perception of predation risk by freshwater snails. Ecological Applications 20: 2089-2095.

5. Carey CC, Ibelings BW, Hoffmann EP, Hamilton DP, Brookes JD (2012) Ecophysiological adaptations that favour freshwater cyanobacteria in a changing climate. Water Research 46: 1394-1407.

6. Fan LM, Barry K, Hu GD, Meng S, Song C, et al. (2016) Bacterioplankton community analysis in tilapia ponds by Illumina high-throughput sequencing. World Journal of Microbiology and Biotechnology 32: 10.

7. Shaari AL, Surif M, Latiff FA, Omar WMW, Ahmad MN (2008) Monitoring of 
Citation: Hou D, Zeng S, Liu J, Yan M, Weng S, et al. (2016) Characterization of Prokaryotic and Eukaryotic Microbial Community in Pacific White Shrimp Ponds. J Aquac Res Development 7: 463. doi: 10.4172/2155-9546.1000463

water quality and microalgae species composition of Penaeus monodon ponds in Pulau Pinang, Malaysia. Tropical Life Sciences Research 22: 51-69.

8. Sakami T, Fujioka Y, Shimoda T (2008) Comparison of microbial community structures in intensive and extensive shrimp culture ponds and a mangrove area in Thailand. Fisheries Science 74: 889-898.

9. Dabade DS, Wolkers-Rooijackers JC, Azokpota P, Hounhouigan DJ, Zwietering $\mathrm{MH}$, et al. (2016) Bacterial concentration and diversity in fresh tropical shrimps (Penaeus notialis) and the surrounding brackish waters and sediment. International Journal of Food Microbiology 218: 96-104.

10. Rungrassamee W, Klanchui A, Maibunkaew S, Chaiyapechara S Jiravanichpaisal $P$, et al. (2014) Characterization of intestinal bacteria in wild and domesticated adult Black Tiger Shrimp (Penaeus monodon). PLoS One 9 e91853.

11. Xiong J, Zhu J, Wang K, Wang X, Ye X, et al. (2014) The temporal scaling of bacterio-plankton composition: High turnover and predictability during shrimp cultivation. Microbial Ecology 67: 256-264

12. Zelles L (1999) Fatty acid patterns of phospholipids and lipopolysaccharides in the characterisation of microbial communities in soil: A review. Biology and Fertility of Soils 29: 111-129.

13. Ramsey PW, Rillig MC, Feris KP, Holben WE, Gannon JE (2006) Choice of methods for soil microbial community analysis: PLFA maximizes powe compared to CLPP and PCR-based approaches. Pedobiologia 50: 275-280.

14. Glenn TC (2011) Field guide to next-generation DNA sequencers. Molecular Ecology Resources 11: 759-769.

15. Margulies M, Egholm M, Altman WE, Attiya S, Bader JS, et al. (2005) Genome sequencing in microfabricated high-density picolitre reactors. Nature 437: 376 380

16. Bates ST, Berg-Lyons D, Caporaso JG, Walters WA, Knight R, et al. (2011) Examining the global distribution of dominant archaeal populations in soil. The ISME journal 5: 908-917.

17. Mangot JF, Domaizon I, Taib N, Marouni N, Duffaud E, et al. (2013) Shortterm dynamics of diversity patterns: evidence of continual reassembly within lacustrine small eukaryotes. Environmental Microbiology 15: 1745-1758.

18. Magoc T, Salzberg SL (2011) FLASH: Fast length adjustment of short reads to improve genome assemblies. Bioinformatics 27: 2957-2963.

19. Caporaso JG, Kuczynski J, Stombaugh J, Bittinger K, Bushman FD, et al (2010) QIIME allows analysis of high-throughput community sequencing data. Nature Methods 7: 335-336.

20. Bokulich NA, Subramanian S, Faith JJ, Gevers D, Gordon JI, et al. (2013) Quality-filtering vastly improves diversity estimates from Illumina amplicon sequencing. Nature Methods 10: 57-59.

21. Edgar RC, Haas BJ, Clemente JC, Quince C, Knight R (2011) UCHIME improves sensitivity and speed of chimera detection. Bioinformatics 27: 21942200.

22. DeSantis TZ, Hugenholtz P, Larsen N, Rojas M, Brodie EL, et al. (2006) Green-genes, A chimera-checked 16S rRNA gene database and workbench compatible with ARB. Applied and Environment Microbiology 72: 5069-5072.

23. Wang Q, Garrity GM, Tiedje JM, Cole JR (2007) Naive Bayesian classifier for rapid assignment of rRNA sequences into the new bacterial taxonomy. Applied and Environment Microbiology 73: 5261-5267.

24. Edgar RC (2004) MUSCLE: A multiple sequence alignment method with reduced time and space complexity. BMC Bioinformatics 5: 1-19.

25. Cai H, Jiang H, Krumholz LR, Yang Z (2014) Bacterial community composition of size-fractioned aggregates within the phycosphere of cyanobacterial blooms in a eutrophic freshwater lake. PLoS One 9: e102879.

26. Kuang JL, Huang LN, Chen LX, Hua ZS, Li SJ, et al. (2013) Contemporary environmental variation determines microbial diversity patterns in acid mine drainage. The ISME journal 7: 1038-1050.

27. Sun Z, Li G, Wang C, Jing Y, Zhu Y, et al. (2014) Community dynamics of prokaryotic and eukaryotic microbes in an estuary reservoir. Scientific Reports 4: 6966

28. De Vargas C, Audic S, Henry N, Decelle J, Mahe F, et al. (2015) Eukaryotic plankton diversity in the sunlit ocean. Science 348: 6237.

29. Rinta-Kanto JM, Konopko EA, DeBruyn JM, Bourbonniere RA, Boyer GL, et al. (2009) Lake Erie microcystis: Relationship between microcystin production, dynamics of genotypes and environmental parameters in a large lake. Harmfu Algae 8: 665-673.

30. Cremen MCM, Martinez-Goss MR, Corre VL, Azanza RV (2007) Phytoplankton bloom in commercial shrimp ponds using green-water technology. Journal of Applied Phycology 19: 615-624

31. Zhang D, Wang X, Xiong J, Zhu J, Wang Y, et al. (2014) Bacterioplankton assemblages as biological indicators of shrimp health status. Ecological Indicators 38: 218-224.

32. Rapala J, Sivonen K (1998) Assessment of environmental conditions that favor hepatotoxic and neurotoxic Anabaena spp. strains cultured under light limitation at different temperatures. Microbial Ecology 36: 181-192.

33. Davis TW, Berry DL, Boyer GL, Gobler CJ (2009) The effects of temperature and nutrients on the growth and dynamics of toxic and non-toxic strains of Microcystis during cyanobacteria blooms. Harmful Algae 8: 715-725.

34. Ke Z, Xie P, Guo L (2008) Controlling factors of spring-summer phytoplankton succession in Lake Taihu (Meiliang Bay, China). Hydrobiologia 607: 41-49.

35. Van Der Westhuizen AJ, Eloff JN (1985) Effect of temperature and light on the toxicity and growth of the blue-green alga Microcystis aeruginosa (UV-006). Planta 163: 55-59.

36. Ohkubo N, Yagi O, Okada M (1993) Studies on the succession of blue green algae, Microcystis, Anabaena, Oscillatoria and Phormidiumin Lake Kasumigaura. Environmental Technology 14: 433-442.

37. Rantala A, Rajaniemi-Wacklin P, Lyra C, Lepisto L, Rintala J, et al. (2006) Detection of microcystin-producing cyanobacteria in Finnish lakes with genusspecific microcystin synthetase gene $E$ (mcyE) PCR and associations with environmental factors. Applied and Environment Microbiology 72: 6101-6110.

38. Wicks R, Thiel P (2002) Environmental factors affecting the production of peptide toxins in floating scums of the Cyanobacterium Microcystis aeruginosa in a hypertrophic African reservoir. Environmental Science \& Technology 9 : 1413-1418.

39. Han S, Zhang Z, Yu L (2003) Using Chlorella and effective microorganisms to optimize aquatic ecological structure and to regulate water quality. Chinese Journal of Applied Ecology 14: 101-104

40. Tang $\mathrm{Y}$, Tao $\mathrm{P}$, Tan J, Mu H, Peng L, et al. (2014) Identification of bacterial community composition in freshwater aquaculture system farming of Litopenaeus vannamei reveals distinct temperature-driven patterns. International Journal of Molecular Sciences 15: 13663-13680.

41. Wang J, Yuan Q, Xie B (2014) Temporal dynamics of cyanobacterial community structure in Dianshan Lake of Shanghai, China. Annals of Microbiology 65 105-113.

42. Murphy LS, Haugen EM (1985) The distribution and abundance of phototrophic ultraplankton in the North Atlantic. Limnology and Oceanography 30: 47-58.

43. Iturriaga R, Mitchell BG (1986) Chroococcoid cyanobacteria: A significant component in the food web dynamics of the open sea. Marine Ecology Progress 28: 291-297.

44. Caiola M, Pellegrini S (1984) Lysis of Microcystis aeruginosa (Kütz.) by Bdellovibrio-like bacteria. Journal of Phycology 20: 471-475.

45. Brenner DJ, Krieg NR, Staley JT, Garrity GM, Boone DR, et al. (2005) Bergey's Manual of Systematic Bacteriology. Springer-Verlag, New York.

46. Kumar PA, Srinivas TNR, Sasikala C, Ramana CV, Sueling J, et al. (2009) Prosthecochloris indica $\mathrm{sp}$ nov., A novel green sulfur bacterium from a marine aquaculture pond, Kakinada, India. Journal of General and Applied Microbiology 55: 163-169.

47. Phlips EJ, Badylak S, Hart J, Haunert D, Lockwood J, et al. (2011) Climatic influences on autochthonous and allochthonous phytoplankton blooms in a subtropical estuary, St. Lucie Estuary, Florida, USA. Estuaries and Coasts 35: 335-352.

48. Rychtecký P, Znachor P (2010) Spatial heterogeneity and seasonal succession of phytoplankton along the longitudinal gradient in a eutrophic reservoir. Hydrobiologia 663: 175-186.

49. Shil J, Ghosh AK, Rahaman SMB (2013) Abundance and diversity of zooplankton in semi intensive prawn (Macrobrachium rosenbergii) farm. Springerplus 2: 1-8. 
Citation: Hou D, Zeng S, Liu J, Yan M, Weng S, et al. (2016) Characterization of Prokaryotic and Eukaryotic Microbial Community in Pacific White Shrimp Ponds. J Aquac Res Development 7: 463. doi: 10.4172/2155-9546.1000463

Page 9 of 9

50. Nakamura Y, Imai I, Yamaguchi A, Tuji A, Not F, et al. (2015) Molecular hylogepny of the widely distributed marine protists, Phaeodaria (Rhizaria, Cercozoa). Protist 166: 363-373.

51. Howe AT, Bass D, Scoble JM, Lewis R, Vickerman K, et al. (2011) Novel cultured protists identify deep-branching environmental DNA clades of Cercozoa: New Genera Tremula, Micrometopion, Minimassisteria, Nudifila, Peregrinia. Protist 162: 332-372.

52. Mantel LH (1983) The biology of Crustacea: 5. Internal anatomy and physiological regulation. New York Academic Press, New York.

53. Alonso-Rodríguez R, Páez-Osuna F (2003) Nutrients, phytoplankton and harmful algal blooms in shrimp ponds: A review with special reference to the situation in the Gulf of California. Aquaculture 219: 317-336.

54. Yusoff FM, Zubaidah MS, Matias HB, Kwan TS (2002) Phytoplankton succession in intensive marine shrimp culture ponds treated with a commercial bacterial product. Aquaculture Research 33: 269-278.
55. Zubkov MV, Sleigh MA, Burkill PH, Leakey RJG (2000) Picoplankton community structure on the Atlantic Meridional Transect: A comparison between seasons. Progress in Oceanography 45: 369-386.

56. Boyd CE (1989) Water quality management and aeration in shrimp farming Auburn University, Alabama.

57. Case M, Leca EE, Leitao SN, Sant Anna EE, Schwamborn R, et al. (2008) Plankton community as an indicator of water quality in tropical shrimp culture ponds. Marine Pollution Bulletin 56: 1343-1352.

58. Michael JV, David LF (1990) Trophic cascades and phytoplankton community structure. Ecology 71: 921-938.

59. Sunagawa S, Coelho LP, Chaffron S, Kultima JR, Labadie K, et al. (2015) Structure and function of the global ocean microbiome. Science 348: 1-7. 